\title{
Trends in herbal usage - a survey study
}

\author{
${ }^{1}$ Alexieva, I.N., ${ }^{1, *}$ Popova, A.T. and ${ }^{2}$ Mihaylova, D.Sp. \\ ${ }^{1}$ Department of Catering and tourism, Economics Faculty, University of food technologies, 26 Maritza \\ Blvd., 4002, Plovdiv, Bulgaria \\ ${ }^{2}$ Department of Biotechnology, Technological Faculty, University of food technologies, 26 Maritza Blvd., \\ 4002, Plovdiv, Bulgaria
}

\author{
Article history: \\ Received: 13 October 2019 \\ Received in revised form: 13 \\ November 2019 \\ Accepted: 27 November \\ 2019 \\ Available Online: 30 \\ November 2019 \\ Keywords: \\ Plants, \\ Survey, \\ Herbal knowledge, \\ Daily Use
}

\section{DOI:}

https://doi.org/10.26656/fr.2017.4(2).346

\begin{abstract}
Folk medicine is quite common for primary health care in Bulgaria, and the tradition of plant usage is of importance for the development of pharmaceutical formulations. The objective of this study was to provide up-to-date information regarding trends in herbal usage among citizens in the city of Plovdiv, Bulgaria. The study involved 114 respondents for a period of 60 calendar days in 2018. Chamomile (Matricaria recutita L.) and thyme (Thymus vulgaris L.) were the most popular plants among the respondents. The common cold is the most frequent example for seeking herbals and other botanicals. Herbal teas are most preferred when it comes to daily consumption. Answers also revealed plants used in households; reasons for herbal consumption, and opinions on common statements concerning herbal stereotypes.
\end{abstract}

\section{Introduction}

Plants and herbs, in particular, have been used for medicinal purposes long before recorded history. Since ancient time, people have tried to find medications to alleviate pain and cure different illnesses. Recently even developed countries, are using medicinal systems that involve herbal drugs and remedies. The contemporary consumer is fascinated with the idea of healthy living, consumption of natural products and "green" lifestyle. For the average person, natural remedies are seen as acceptable, accessible, inexpensive and available. There is a rise in the organic food demand and the consumer is turning to naturally produced products. Many products are boosted with functional ingredients to meet the health -conscience consumer's demand. Consumers are turning to food to fill needs beyond hunger and cravings. Herbals and botanicals, considered sustainable and eco-friendly, have been used for thousands of years. The term herb refers not only to herbaceous plants but also to the leaves, bark, roots, seeds, fruits and flowers of shrubs and trees.

Herbal teas, also called tisanes, are beverages made from the infusion or decoction of herbs, spices, or other plant material (seeds, roots, etc.), commonly consumed for its therapeutic and energizing properties (Ravikumar, 2014). Herbal teas should not be confused with true teas prepared from the cured leaves of Camellia sinensis L. (e.g., black, green, white, yellow, and Oolong). Throughout history, many nations (Greek, Roman, Egyptian, Chinese) have turned to natural alternatives as remedies. Currently, the EU market offers a wide variety of food supplements from botanicals and derived preparations made from plants, algae, fungi or lichens. Such products are typically labelled as natural and a variety of claims are made regarding possible health benefits. They can be bought in pharmacies, supermarkets, specialist shops, farmers markets and via the Internet. Plant deriving pharmaceuticals stand for over US \$ 60 billion of annual profit worldwide (International Trade Administration, 2016). This market is growing rapidly and is built over traditions passed down from generation to generation or recommended by folk healers. The EU legislation defines herbal medicinal products as any medicinal product, exclusively containing as active ingredients one or more herbal substances, one or more herbal preparations, or a combination of the two (Directive 2001/83/EC).

Phytochemicals are classified as primary or secondary constituents, depending on their role in plant metabolism. Primary constituents include the common sugars, amino acids, proteins, purines and pyrimidines of nucleic acids, lipids and chlorophyll. Secondary constituents are the remaining plant chemicals such as 
alkaloids, terpenes, flavonoids, lignans, plant steroids, curcumines, saponins, phenolics, flavonoids and glucosides (Jenzer and Sadeghi, 2016). Phenolic compounds exhibit a wide range of physiological properties, such as anti-allergenic, anti-atherogenic, antiinflammatory, anti-microbial, antioxidant, antithrombotic, cardioprotective and vasodilatory effects (Middlieton et al., 2000, Manach et al., 2005; Puupponen-Pimia et al., 2008). The active substances affect the human body differently - temperature-limiting, diuretic, pain-relieving, balancing blood pressure or hormones, anti-inflammatory, etc.

Plants are important to mankind not only environmentally and industrially, but also medicinally. The aim of this study was to survey the consumer's attitude to herbal usage to help deepen the knowledge about the role of herbs and other botanicals in daily health maintenance. The study also intended to document reliable information in order to pinpoint ideas for future scientific research.

\section{Materials and methods}

A questionnaire was developed and piloted by twenty people. According to the replies, the questionnaire was modified. Few questions were added and others were reworded. The study was carried out in the Plovdiv region, Bulgaria and the questionnaire was provided only in Bulgarian. One hundred and fourteen consenting adult male and female subjects took part in the study. The respondent-to-item ratio was 5:1. For the survey, a representative sampling method was applied based on personal contact. The duration of the sociological survey covered a period of sixty days between June-July in 2018. The method for gathering information was a direct individual poll. A 22-question questionnaire was developed, seven of which were sociodemographic, and 15 were focused on the daily use of herbals and other botanicals. The analysis considered the consumers' views, reflected in the responses of closed and open questions of the questionnaire. There was a space made available in the questionnaire for free comments of respondents. The questionnaire elicited information about including plants in daily life and their use as remedies. Statistical analysis was done using the statistical package of MS Excel 2016. Simple descriptive statistics were used together with Chi-square $\left(\chi^{2}\right)$ test. The chosen level of significance was set at $\mathrm{P}<0.05$. Unanswered questions were treated as missing values.

\section{Results and discussion}

A total of 114 respondents participated in the study made up of $32 \%$ males and $68 \%$ females. As previously proven, women are more likely to participate in surveys than men (Curtin et al., 2000). Participants from different age groups took part in the survey, with the most abundant age group being between 21 and 30 years old. Respondents of $78 \%$ appeared to be residents of the city of Plovdiv. Table 1 is a visual presentation of the socio-demographic characteristics of the respondents.

Table 1. Socio-demographic characteristics of respondents

\begin{tabular}{|c|c|}
\hline Indicator & Percentage $(\%)$ \\
\hline \multicolumn{2}{|l|}{$\operatorname{Sex}$} \\
\hline Male & 32 \\
\hline Female & 68 \\
\hline \multicolumn{2}{|c|}{ Age in years } \\
\hline$<20$ years old & 3 \\
\hline 21-30 years old incl. & 31 \\
\hline $31-40$ years old incl. & 23 \\
\hline 41-50 years old incl. & 17 \\
\hline $51-60$ years old incl. & 14 \\
\hline $61-70$ years old incl. & 8 \\
\hline $71-80$ years old incl. & 4 \\
\hline $80+$ years old & 0 \\
\hline \multicolumn{2}{|c|}{ Education level } \\
\hline No education & 1 \\
\hline Primary & 3 \\
\hline Secondary & 40 \\
\hline Higher & 56 \\
\hline \multicolumn{2}{|c|}{ Living conditions } \\
\hline Single & 16 \\
\hline With parents & 18 \\
\hline Co-habiting/married no children & 33 \\
\hline Co-habiting/married with children & 33 \\
\hline \multicolumn{2}{|c|}{ Employment } \\
\hline Working & 71 \\
\hline Unemployed & 4 \\
\hline Pensioner & 10 \\
\hline Student & 15 \\
\hline
\end{tabular}

Respondents answered questions concerning their daily herbal usage and habits. The stress responses have been important for human survival and for protection of the body so a question evaluating daily stress was present in the questionnaire. Respondents of $56 \%$ believed that they suffered from daily stress, $29 \%$ determined their lifestyle as stress-free and $15 \%$ could not decide.

A series of studies of women and men concluded that gender roles and psychological factors are more important than biological factors for the sex differences in stress responses (Lundberg, 2005).

Chronic disease is defined as a long-lasting condition affecting the patient lifestyle so the respondents were asked about their health status. A total of $74 \%$ considered themselves healthy, $3 \%$ could not decide if they are suffering from chronic diseases, and $23 \%$ claimed that they have been diagnosed with one or more of the following conditions: asthma, sinusitis, diabetes type 2, allergies, heart conditions, thyroid gland diseases, 
70

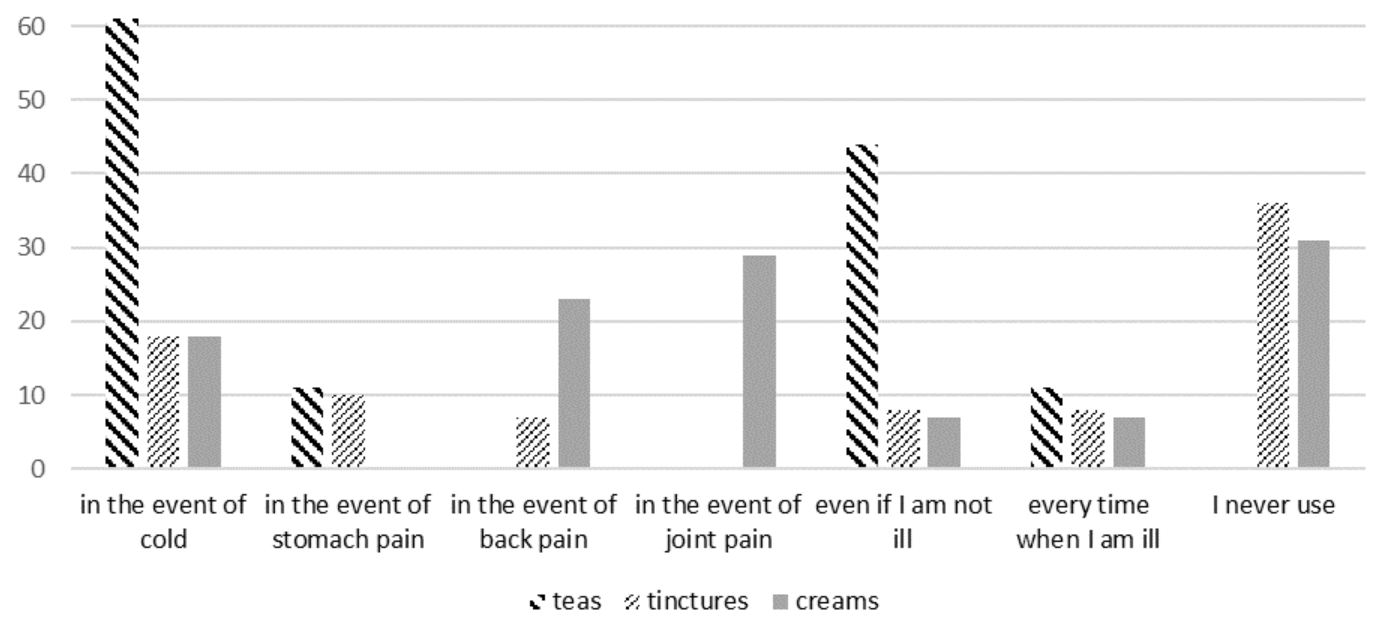

thrombophlebitis, pyelonephritis, pharyngitis, depression, and glaucoma.

Only $25 \%$ of respondents regularly used herbs or other botanicals for treatment, prevention of disease, increasing the tone or the immunity; $67 \%$ sometimes used plant, $3 \%$ have not used but are willing to do so if needed; 3\% have never felt the need to use herbaceous products and $2 \%$ claimed that have never used and not willing to try herbs or other botanicals for treatment. Traditional systems of medicines, including herbal medicines, have been used for many centuries. In 2010 the WHO published Traditional Herbal Remedies for Primary Health Care where recipes are given for the treatment of various conditions. Other conducted surveys concern the usage of medicinal plants by traditional healers (South Africa) in order to pinpoint those medicinal plants that can be used for the development of pharmaceutical products as well as to attract the attention to scientist towards their research (Mahwasane et al., 2013). Kigen et al. (2019) have also focused on documenting plants used by traditional healers in Kenya and have collected information about the usage of 47 plant species belonging to 31 families. Macia et al. (2004) have identified that people prepare remedies from plants and the highest number of species and applications were reported for digestive system disorders, rheumatism, sprains, swellings, urological, and gynecological problems.

Plants have to be gathered very carefully, especially if they are intended to be used as a healing agent. Popova and Mihaylova (2018) have described very thoroughly the need of proper medicinal plants exploitation. This is probably the reason why only $30 \%$ of the survey participants gather their herbs on their own and an estimated $70 \%$ buy their herbs from supermarkets, local markets or pharmacies.
When asked if they can name up to six medicinal plants the respondents do not hesitate to name even more plants they have heard of or have used. The most abundant plant in their list is chamomile (Matricaria recutita L.) (48\%) followed by thyme (Thymus vulgaris L.) $(41 \%)$ and St. John's worth (Hypericum perforatum L.) (35\%). Other frequently named plants were peppermint (Mentha piperita L.) (26\%); linden (Tilia tomentosa L.) (2\%); lemon balm (Melissa officinalis L.) (1\%); nettle (Urtica dioica L.) and oregano (Origanum vulgare L.) (both 15\%). All of the abovementioned plants are proven to possess beneficial properties. One of the most recognized plant to humankind is chamomile. It is reported to possess anti-inflammatory, antioxidant, mild astringent and healing properties (Srivastava et al., 2010). You can also treat wounds, ulcers, eczema, gout, skin irritations, bruises and burns with chamomile (Awang, 2009). Some of the properties that thyme has are antiseptic, antimicrobial, astringent, carminative, and disinfection (Prasanth et al., 2014). The primary indication of St. John's wort products is depression, according to modern diagnostic criteria (Linde, 2009). Digestive disorders and problems with the nervous system can be treated with peppermint because of its antitumor and antimicrobial properties, antiallergenic, etc. (Keifer et al., 2008; Saeidnia et al., 2011). Lemon balm is mainly characterized by its anti-depressive qualities (Hoffmann, 2003).

Some of the ways herbs can be used are presented in Figure 1.

Respondents of $82 \%$ drank their herbs as teas, $20 \%$ relied on the supplement intake in the form of powder or tablets. An estimated $18 \%$ used herbs as a locally applied cream. There are traditions in tea consumption in many countries like tea ceremonies in Japan and the English afternoon tea. Tea drinking is very often associated with cold treatments. This is proven by the answer given by 
$61 \%$ of the respondents who only drink tea in the event of cold. Another $44 \%$ consume tea beverages at any occasion, even if they are not ill. A total of $11 \%$ relied on tea every time they are not feeling ok. In 2007, a research team has determined that a specific formulation of Camellia sinensis is an effective dietary supplement for preventing cold and flu symptoms (Rowe et al., 2007).

By definition, tinctures are liquid extracts made from herbs dissolved in ethanol, that a person takes orally. They are considered easy and convenient to use. It is assumed that their action in the body is quicker compared to other extraction techniques. However, $36 \%$ of the respondents in the current survey do not use tinctures in their daily routine. Only $29 \%$ use tinctures to prevent cold symptoms, and another $8 \%$ use tinctures to cope with dental problems. It has to be mentioned that during this survey a few limitations have been encountered. For example, some respondents have been using herbs in their everyday life without considering it. A person might drink herbal tea with associating it to its beneficial properties.

All of the survey respondents are familiar with different extraction techniques. Respondents of $76 \%$ knew what a decoction is; $64 \%$ knew what an infusion is and another $26 \%$ knew the definition of tincture. Decoction and infusion are the most common household tea preparation techniques. Tea brewing in different countries has its traditions like the Japanese "silk stocking tea", brewed in a large tea sock and the Russian "zavarka" prepared in special teapots.
Nowadays, there are many sources where people can find information about herbs and their usage. About $66 \%$ of the respondents used the Internet as a reliable information source, while $60 \%$ sought information from friends and family members. About 29\% searched information in books and $51 \%$ thought that there is enough information in newspapers and magazines. The Internet being the most popular place for information search is understandable considering the fact that there you can find a large number of reliable sources like research papers, online books, sites of trusted and respected manufactures, etc. People have always trusted personal recommendation that is probably why there is a high percentage relying on family and friends, especially the elderly relatives' plant knowledge.

Table 2 shows some of the most commonly used herbs and their respondents' usage.

The results showed that there is a rather extensive herbal knowledge among the respondents. Three of the abovementioned herbs appeared to be rather unpopular among the respondents. This can be due to the different popular names herbs have in different regions and countries. Otherwise, tansy (Tanacetum vulgare L.), water pepper (Polygonum hydropiper L.) and bladder campion (Silene vulgaris L.) are quite popular to the science community. Silene vulgaris is widespread and native to Europe. Polygonum hydropiper is reported to possess high antioxidant potential and can be related to the presence of high molecular weight phenolics (Ayaz et al., 2014). Tanacetum vulgare extracts are widely used

Table 2. Herb knowledge and usage

\begin{tabular}{|c|c|c|c|}
\hline \multirow{2}{*}{ Name of the herb } & I know this herb & I have used the herb & I have not heard of the herb \\
\hline & \multicolumn{3}{|c|}{$\%$} \\
\hline Nettle (Urtica dioica L.) & 53 & 74 & 0 \\
\hline Tansy (Tanacetum vulgare L.) & 25 & 0 & 68 \\
\hline Water pepper (Polygonum hydropiper L.) & 23 & 1 & 70 \\
\hline Bladder campion (Silene vulgaris L.) & 21 & 2 & 72 \\
\hline Common centaury (Centaurium erythraea Rafn.) & 60 & 26 & 16 \\
\hline Rose hip (Rosa canina L.) & 42 & 80 & 0 \\
\hline Chamomile (Matricaria recutita L.) & 40 & 82 & 0 \\
\hline St. John's-wort (Hypericum perforatum L.) & 43 & 73 & 2 \\
\hline Elderberry (Sambucus nigra L.) & 60 & 45 & 4 \\
\hline Thyme (Thymus vulgaris L.) & 38 & 79 & 0 \\
\hline Lemon balm (Melissa officinalis L.) & 47 & 63 & 0 \\
\hline Yarrow (Achilea millefolium L.) & 51 & 50 & 4 \\
\hline Wild basil (Clinopodium vulgare L.) & 53 & 30 & 19 \\
\hline Hawthorn (Crataegus monogyna Jacq.) & 65 & 40 & 4 \\
\hline Plantain (Plantago major L.) & 58 & 35 & 11 \\
\hline Coltsfoot (Tussilago farfara L.) & 48 & 24 & 28 \\
\hline Chicory (Cichorium intybus L.) & 32 & 4 & 57 \\
\hline Slavia (Salvia officinalis L.) & 50 & 34 & 21 \\
\hline $\begin{array}{l}\text { Horseradish (Armoracia rusticana G. Gaertn., B. Mey. and } \\
\text { Scherb.) }\end{array}$ & 58 & 35 & 10 \\
\hline Mursal (mountain) tea (Sideritis scardica L.) & 53 & 53 & 7 \\
\hline
\end{tabular}


I do not use herbs because I do not know how

I gahter herbs every year

I often use herbal teas

The herbs I gather myself are better from the ones I buy

Herbs help the body to fight against stress

I will consume more herbs if there is more information..

We have a tradition of gathering and using herbs

Daily herbal intake leads to fewer illnesses

Most medicines are made from herbs

Herbs act better than medicine

Herbs do not harm the body

Some herbs are not suitable for children

Herbs act slowlier than medication

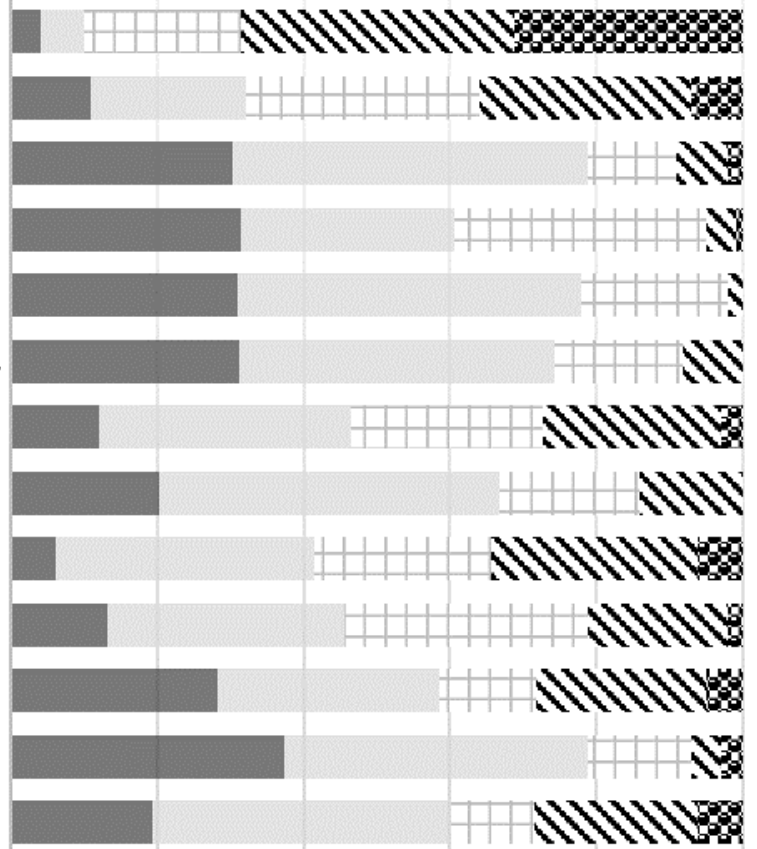

I completely agree

I agree up to a point

$0 \%$

No opinion

$20 \% \quad 40 \%$

$60 \% \quad 80 \%$

I completely disagree

Figure 2. Opinion on some common statements

as a diuretic confirming their ethno pharmacological use (Lahlou et al., 2007).

The survey also investigated the respondents' opinion about some common statements (Figure 2). About $59 \%$ agreed that herbs act more slowly than medicine.

The treatment of infections and health disorders with herbal medicines involves active natural products (secondary metabolites) mostly of low molecular weight and great structural diversity, which are typical for all plants. The description and understanding the mode of action on secondary metabolites still challenges pharmacology today (Wink, 2015). About 78\% said that some herbs are not suitable for children to consume. Even though herbal products are often regarded as natural, they can still interact with other medication and cause reactions (Licata et al., 2013). A recent study revealed that herbal medicinal products are mainly used for the treatment of coughs and colds among children (Du et al., 2014). A statement that revealed the modern herbal consumer as a knowledgeable one is a fact that $41 \%$ were aware of the fact that herbs comprise of some medicines.

Probably the most common example of plant deriving medicine is aspirin, obtained from Spiraea plants, which contains salicylic acid. About $78 \%$ of the respondents agreed that herbs help the body fight against stress. The human body has several mechanisms to counteract oxidative stress, by producing natural antioxidants or by submitting them to the outside through food and/or supplements.

In the event of oxidative stress, the body activates redox-signaling mechanisms that mobilize the antioxidants contained in the cells or their reserves. Upon restoration of the antioxidant protection, the normal physiological condition of the body is preserved. In case of antioxidant deficiency, tissue/organ damage occurs in/directly, leading to their respective malfunction (Halliwell et al., 2000).

The mobilization of antioxidants in response to oxidative stress is a dynamic process in which, food intake can significantly affect the health (Rao et al., 2006). Researchers exhibit strong scientific interest in the antioxidant properties of polyphenols and the possibility of increasing the antioxidant defense system by including plants rich in them in the diet. It has been shown in vitro, that flavonoids influence the inflammatory cells and the activity of many enzyme systems, and there are quite a few facts about the in vivo effects (Borchardt et al., 2009). Much of the evidence for the preventive effects of polyphenols on many diseases are in vitro assays or animal experiments. They are often carried out in doses higher than those of human intake through food (Scalbert et al., 2005).

\section{Conclusion}

In conclusion, the findings from this study showed that herbs and other botanicals are a part of the modern consumer's lifestyle as it used to be ages ago. More than 
twenty plants have been documented in terms of their usage. Chamomile (Matricaria recutita L.) and thyme (Thymus vulgaris L.) were the most popular plants among the respondents. Tea brewing is the most common way herbs are used in the average household. The internet, as well as personal recommendation, are the sources where people seek for reliable information about herbal usage. Typical herbal consumption was reported for pain relief and illness treatment. Herbal consumption would increase if more information about their beneficial properties were commercially available, thus, scientific research in the field has an important role in consumer's recommendation and education.

\section{Conflict of Interest}

The authors declare no conflict of interest.

\section{Acknowledgments}

The authors gratefully acknowledge the financial support of the Ministry of Education and Science (Bulgaria), grant agreement No. DM 07/2.

\section{References}

Awang, D.V.C. (2009). Tyler's Herbs of Choice. The therapeutic use of phytomedicinals. $3^{\text {rd }}$ ed. Florida, USA: CRC Press, Taylor and Francis Group. https:// doi.org/10.1201/9780789038739

Ayaz, M., Junaid, M., Ahmed, J., Ullah, F., Sadiq, A., Ahmad, S. and Imran, M. (2014). Phenolic contents, antioxidant and anticholinesterase potentials of crude extract, subsequent fractions and crude saponins from Polygonum hydropiper L. BMC Complementary and Alternative Medicine, 14, 145. https://doi.org/10.1186/1472-6882-14-145

Borchardt, J., Wyse, D., Sheaffer, C., Kauppi, K., Fulcher, R., Ehlke, N., Biesboer, D., Russell, F. and Bey, R. (2009). Antioxidant and antimicrobial activity of seed from plants of the Mississippi river basin. Journal of Medicinal Plants Research, 3(10), 707-718.

Curtin, R., Presser, S. and Singer, E. (2000). The effects of response rate changes on the index of consumer sentiment. Public Opinion Quarterly, 64, 413-428. https://doi.org/10.1086/318638

Directive 2001/83/EC of the European Parliament and the Council of 6 November 2001 on the Community code relating to medicinal products for human use. (2001). Official Journal of the European Union, L311, 67-128.

Du, Y., Wolf, I-K., Zhuang, W., Bodemann, S., Knöss, W. and Knopf, H. (2014). Use of herbal medicinal products among children and adolescents in Germany. BMC Complementary and Alternative Medicine, 14, 218. https://doi.org/10.1186/14726882-14-218

Halliwell, B., Clement, V. and Long, H. (2000). Hydrogen Peroxide in the human body, FEBS Letters, 486(1), 10-13. https://doi.org/10.1016/S0014 $-5793(00) 02197-9$

Hoffmann, D. (2003). Medical herbalism: the science and practice of herbal medicine. Rochester, Vermont, USA: Healing Arts Press.

International Trade Administration (ITA). (2016). 2016 Top Markets Report Pharmaceuticals. A market assessment tool for U.S. Exporters. USA: ITA

Jenzer, H. and Sadeghi, L. (2016). Phytochemicals: Sources and biological functions. Journal of Pharmacognosy and Phytochemistry, 5(5), 339-434.

Keifer, D., Ulbricht, C., Abrams, T.R., Basch, E., Giese N., Defranco Kirkwood, C., Miranda, M. and Woods, J.L. (2008). Peppermint (Mentha Piperita) an evidence-based systematic review by the natural standard research collaboration. Journal of Herbal Pharmacotherapy, 7(2), 91-143. https:// doi.org/10.1080/J157v07n02_07

Kigen, G., Kamuren, Z., Njiru, E., Wanjohi, B. and Kipkore W. (2019). Ethnomedical survey of the plants used by traditional healers in Narok County, Kenya. Evidence-Based Complementary and Alternative Medicine, 2019, 8. https:// doi.org/10.1155/2019/8976937

Lahlou, S., Tahraoui, A., Israili, Z. and Lyoussi, B. (2007). Diuretic activity of the aqueous extracts of Carum carvi and Tanacetum vulgare in normal rats. Journal of Ethnopharmacology, 110(3), 458-463. https://doi.org/10.1016/j.jep.2006.10.005

Licata, A., Macaluso, F.S. and Craxì, A. (2013). Herbal hepatotoxicity: a hidden epidemic. International Journal of Medical Sciences, 8(1), 13-22. https:// doi.org/10.1016/j.jep.2006.10.005

Linde, K. (2009). St John's Wort - an overview, Forsch Komplementmed, 16, 146-155. https:// doi.org/10.1159/000209290

Lundberg, U. (2005). Stress hormones in health and illness: The roles of work and gender. Psychoneuroendocrinology, 30(10), 1017-1021. https://doi.org/10.1016/j.psyneuen.2005.03.014

Macia, M., Garcia, E. and Vidaurre, P. (2004). An ethnobotanical survey of medicinal plants commercialized in the markets of $\mathrm{La} \mathrm{Paz}$ and $\mathrm{El}$ Alto, Bolivia. Journal of Ethnopharmacology, 97(2), 337-350. https://doi.org/10.1016/j.jep.2004.11.022

Mahwasane, S., Middleton, L. and Boaduo, N. (2013). 
An ethnobotanical survey of indigenous knowledge on medicinal plants used by the traditional healers of the Lwamondo area, Limpopo province, South Africa. South African Journal of Botany, 88, 69-75. https://doi.org/10.1016/j.sajb.2013.05.004

Manach, C., Williamson, G., Morand, C., Scalbert, A. and Rémésy, C. (2005). Bioavailability and bioefficacy of polyphenols in humans. I. Review of 97 bioavailability studies. American Journal of Clinical Nutrition, 81(1), 230-242. https:// doi.org/10.1093/ajcn/81.1.230S

Middleton, E., Kandaswami, C. and Theoharides, T.C. (2000). The effects of plant flavonoids on mammalian cells: implications for inflammation, heart disease, and cancer. Pharmacological Reviews, 52, 673-751.

Popova, A. and Mihaylova, D. (2018). A review of the medicinal plants in Bulgaria - collection, storage, and extraction techniques. Asian Journal of Pharmaceutical and Clinical Research, 11(3), 28-35. https://doi.org/10.22159/ajpcr.2018.v11i3.22994

Prasanth, R., Ravi, V.K., Varsha P.V. and Satyam, S. (2014). Review on Thymus vulgaris traditional uses and pharmacological properties. Medicinal and Aromatic Plants, 3(4), 1-3.

Puupponen-Pimiä, R., Nohynek, L., Ammann, S., Oksman-Caldentey, K.M. and Buchert, J. (2008). Enzyme-assisted processing increases antimicrobial and antioxidant activity of bilberry. Journal of Agricultural and Food Chemistry, 56(3), 681-688. https://doi.org/10.1021/jf072001h

Rao, A., Bharani, M. and Pallavi, V. (2006). Role of antioxidants and free radicals in health and disease. Advances in Pharmacology and Toxicology, 7, 2938.

Ravikumar, C. (2014). Review on herbal teas. Journal of Pharmaceutical Sciences and Research, 6(5), 236238.

Rowe, C.A., Nantz, P.M., Bukowski, F.J. and Percival, S. (2007). Specific Formulation of Camellia sinensis prevents cold and flu symptoms and enhances $\gamma \delta \mathrm{T}$ cell function: A randomized, double blind, placebocontrolled study, Journal of the American College of Nutrition, 26(5), 445-452. https:// doi.org/10.1080/07315724.2007.10719634

Saeidnia, S., Gohari, A., Mokhber-Dezfuli, N. and Kiuchi, F. (2011). A review on phytochemistry and medicinal properties of the genus Achillea. DARU: Journal of Faculty of Pharmacy, Tehran University of Medical Sciences, 19(3), 173-186.

Scalbert, A., Johnson, I. and Saltmarsh, M. (2005). Polyphenols: antioxidants and beyond, American
Journal of Clinical Nutrition, 81(1), 215-217. https://doi.org/10.1093/ajcn/81.1.215S

Srivastava, J.K., Shankar, E. and Gupta, S. (2010). Chamomile: A herbal medicine of the past with bright future. Molecular medicine reports, 3(6), 895901. https://doi.org/10.3892/mmr.2010.377

Wink, M. (2015). Modes of Action of Herbal Medicines and Plant Secondary Metabolites. Medicines, 2, 251286. https://doi.org/10.3390/medicines2030251 